\title{
Prognostic factors for salvage radiotherapy with an analysis of post-prostatectomy PSA kinetics
}

\author{
Brian J. Gebhardt ${ }^{1}$, Andrew M. McDonald ${ }^{2}$, Sejong Bae ${ }^{2}$, Karan P. Singh ${ }^{2}$, Rojymon Jacob ${ }^{2}$, \\ Michael C. Dobelbower ${ }^{2}$, Eddy S. Yang ${ }^{2}$, John B. Fiveash ${ }^{2}$ \\ 1. Department, University of Texas Southwestern, Austin, United States. 2. Department of Radiation Oncology, University \\ of Alabama, Birmingham, United States.
}

Correspondence: John B. Fiveash. Address: 619 19th St. South, Birmingham, AL 35249-6832, United States. Email: jfiveash@uab.edu.

Received: April 4, 2013

DOI : $10.5430 /$ jst.v3n4p32

Accepted: August 8, 2013

URL: http://dx.doi.org/10.5430/jst.v3n4p32
Online Published: August 19, 2013

\section{Abstract}

Objectives: To identify prognostic factors for biochemical control including post-prostatectomy prostate-specific antigen (PSA) kinetics in prostate cancer patients undergoing salvage radiotherapy (SRT).

Methods and Materials: Ninety patients who received SRT following radical prostatectomy (RP) were retrospectively analyzed to determine factors associated with biochemical failure.

Results: Median follow-up was 30 months (range 6-120). The projected 3-year biochemical freedom from progression (bFFP) was 70\%. Factors significantly associated with biochemical failure on univariate analysis included Gleason score (GS), seminal vesicle invasion (SVI), a length of time from prostatectomy to SRT of less than 12 months, pre-RT PSA greater than $1.0 \mathrm{ng} / \mathrm{mL}$, a persistently detectable PSA following RP, PSA doubling time (PSADT) of 6 months or less, PSA velocity (PSAV) of $1.0 \mathrm{ng} / \mathrm{mL} / \mathrm{y}$ or greater, and a rising PSA trend during treatment. There was a trend toward decreased bFFP among patients with pathologic tumor stage of T3-T4 $(p=0.136)$ and positive surgical margins $(p=0.301)$. Pre-RT PSA was found to be a significant predictor of progression with a HR of 3.659 (CI 1.981-8.755) for each increase in PSA of $1.0 \mathrm{ng} / \mathrm{mL}$.

Conclusion: Early consideration of SRT should be given for patients with high-risk features and rising PSA. Clinical trials evaluating systemic therapy should be considered for patients with persistently detectable PSA after RP or a rising PSA trend during SRT.

\section{Key words}

Prostatectomy, Radiation therapy, PSA kinetics

\section{Introduction}

Retrospective data have shown that use of SRT can achieve biochemical control in men with rising PSA following RP ${ }^{[1]}$. Trock et al. found a significant difference in prostate cancer-specific survival between patients with rising PSA who received SRT compared with those who did not ${ }^{[2]}$. SRT is associated with a low but significant risk of late side effects ${ }^{[3]}$, which suggests a need for effective patient selection. There is currently no imaging study that can conclusively determine which patients have locally recurrent disease as opposed to occult metastasis. Investigators have identified prognostic 
characteristics and developed nomograms to predict response to SRT ${ }^{[4]}$, but more data is needed to accurately predict treatment outcomes.

Table 1. Patient and treatment characteristics $(\mathrm{n}=90)$

\begin{tabular}{|c|c|c|}
\hline & Median & Range \\
\hline Age, $y$ & 61.4 & $44.2-78.6$ \\
\hline iPSA, ng/mL & 8.6 & $2.1-59.9$ \\
\hline Time from RP to $\mathrm{RT}, \mathrm{m}$ & 38 & $(3.0-162)$ \\
\hline Pre-RT PSA, ng/mL & 0.4 & $0-6.3$ \\
\hline PSADT, $m$ & 6.7 & $0.9-89.0$ \\
\hline $\mathrm{PSAV}, \mathrm{ng} / \mathrm{mL} / \mathrm{y}$ & 0.4 & $0-4.5$ \\
\hline \multirow[t]{2}{*}{ Prostate Dose, Gy } & 68.4 & $61.2-75.6$ \\
\hline & $\mathrm{N}$ & $\%$ \\
\hline \multicolumn{3}{|l|}{ Elective Nodal RT } \\
\hline Yes & 7 & 7.78 \\
\hline No & 83 & 92.22 \\
\hline \multicolumn{3}{|c|}{ Androgen deprivation therapy } \\
\hline Yes & 21 & 23.33 \\
\hline No & 69 & 76.67 \\
\hline \multicolumn{3}{|l|}{ Tumor stage } \\
\hline 2 & 40 & 50.63 \\
\hline $3 a$ & 26 & 32.91 \\
\hline $3 b$ & 11 & 13.92 \\
\hline 4 & 2 & 2.53 \\
\hline \multicolumn{3}{|l|}{ Nodal stage } \\
\hline No & 53 & 55.89 \\
\hline N1 & 3 & 3.33 \\
\hline NX & 34 & 37.78 \\
\hline \multicolumn{3}{|l|}{ Extracapsular extension } \\
\hline Positive & 34 & 43.94 \\
\hline Negative & 45 & 56.96 \\
\hline \multicolumn{3}{|l|}{ Seminal vesicle invasion } \\
\hline Positive & 12 & 15.19 \\
\hline Negative & 67 & 84.81 \\
\hline \multicolumn{3}{|l|}{ Gleason score } \\
\hline$\leq 6$ & 25 & 30.12 \\
\hline 7 & 45 & 54.22 \\
\hline$\geq 8$ & 13 & 15.66 \\
\hline \multicolumn{3}{|l|}{ Surgical margin status } \\
\hline Positive & 42 & 55.26 \\
\hline Negative & 34 & 44.74 \\
\hline
\end{tabular}

Abbreviations: PSA, prostate-specific antigen; iPSA, pre-prostatectomy PSA; pre-RT PSA, PSADT, PSA doubling time; PSAV, PSA velocity 
The clinical value of serum PSA as a marker for identifying disease progression is established in the literature. Investigators have paid much attention to using PSA kinetics to predict the outcome of RT in the definitive setting ${ }^{[5-6]}$. This study was performed to evaluate prognostic factors in patients undergoing SRT, defined as RT performed on patients with rising or persistently elevated PSA following radical prostatectomy. Identifying characteristics associated with biochemical progression following SRT is important for recognizing traits associated with a low chance for successful salvage, improving patient selection, and optimizing the timing of post-operative RT. We hypothesize that various measures of post-prostatectomy PSA kinetics will be useful markers for predicting biochemical control of prostate cancer.

\section{Methods and materials}

\subsection{Patient population}

Between July 2001 and October 2011, 129 patients underwent RT following radical prostatectomy at the University of Alabama, Birmingham Medical Center and the Birmingham VAMC. Patients were routinely followed with serial PSA measurements following radical prostatectomy. Ninety-nine patients treated with RT because of PSA measurements that were rising or persistently elevated $>0.1 \mathrm{ng} / \mathrm{mL}$ following RP were considered to have been treated with salvage intent and were the subject of this investigation. Adjuvant RT is defined in this paper as the use of post-operative RT due to the presence of positive surgical margins or extra-prostatic disease spread to reduce the risk of biochemical or clinical disease recurrence. Patients with PSA $\leq 0.1 \mathrm{ng} / \mathrm{mL}$ and treated within 1 year of RP were considered to have been treated with adjuvant intent and were not considered for analysis. We excluded an additional 9 patients from analysis due to insufficient follow-up or use of long-term hormonal deprivation. Patients who received short-term hormonal deprivation were considered for analysis. The study was approved by the University of Alabama, Birmingham Institutional Review Board.

We retrospectively reviewed all medical records, PSA values, and pathology reports of the 90 evaluable patients. Details of patient and treatment characteristics are listed in Table 1.

The median patient age was 61 years (range, 44-78). Pathological stages of patients were T2 (50\%), T3 (47\%), or T4 (3\%). The median PSA level before prostatectomy was $8.6 \mathrm{ng} / \mathrm{mL}$ (range, 2.1-59.9). The median time between surgery and RT was 38 months (range, 3-162). The median PSA level prior to SRT was $0.4 \mathrm{ng} / \mathrm{mL}$ (range, 0.04-6.3). PSADT and PSAV were calculated for all patients with at least two measureable PSA recordings between prostatectomy and SRT. PSADT and PSAV were calculated using the nomogram developed at Memorial Sloan-Kettering Cancer Center ${ }^{[7]}$. Any PSA values obtained during the use of short-term androgen deprivation therapy (ADT) were excluded from calculations.

\subsection{Treatment characteristics}

Patients were treated with external beam RT to the prostate fossa to a median dose of 68.4 Gy (61.2-75.6) at 1.8 Gy per fraction. Seven patients (8\%) received elective pelvic nodal irradiation at a dose of either 45 or $50.4 \mathrm{~Gy}$. Twenty-one patients (23\%) received neoadjuvant and/or concurrent ADT as a component of treatment. The median length of ADT was 7 months (range, 5-24).

\subsection{Statistical analysis}

The study's primary end-point was bFFP, measured as the time from start of RT to biochemical failure. Biochemical failure after RT was defined as a post-radiotherapy PSA value of $\geq 0.4 \mathrm{ng} / \mathrm{mL}$ and rising (two consecutive rises with one being at least $0.4 \mathrm{ng} / \mathrm{mL}$ ). The time of failure was recorded as the date of the defining PSA value. The threshold value was chosen because it has been shown to best predict later clinical progression in post-prostatectomy patients ${ }^{[8]}$. Several variables of interest were measured including pre-RT PSA, PSA kinetics, GS, presence of extracapsular extension (ECE) and SVI, surgical margin status, and the use of ADT. 
The Kaplan-Meier method was used to estimate the rates of bFFP. Associations of patient factors with time to biochemical failure were assessed with the log-rank test. Multivariate Cox regression analysis was performed on a subset of 56 of the 90 patients with complete pathological data to evaluate prognostic factors associated with biochemical control. Relationships with outcomes were summarized with Hazard Ratio (HR) and the 95\% confidence interval (CI). Statistical significance was determined at the 5\% level. Analyses were conducted using SAS 9.3.

\section{Results}

The median follow-up time for the 90 patients receiving SRT was 30 (range, 6-120) months from time of RT. On last follow-up, 65 of 90 patients (72\%) were free from biochemical progression. The projected overall 3-year bFFP was $70 \%$ (Figure 1).

Figure 1. Product-Limit Estimate of bFFP after Salvage Radiotherapy

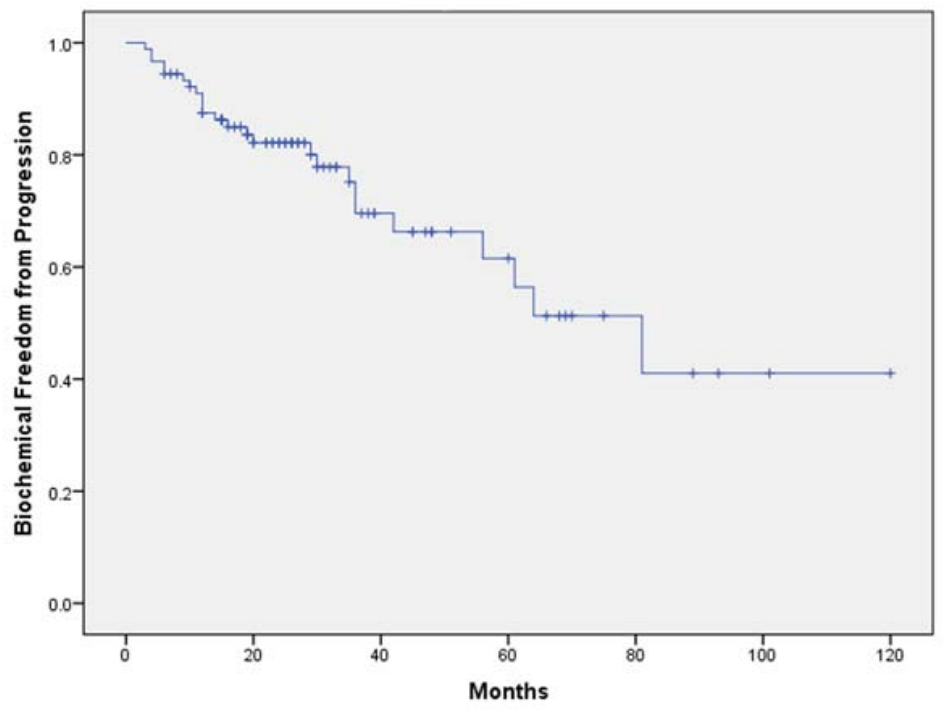

Figure 2. Product-Limit Estimate of bFFP by Gleason Score

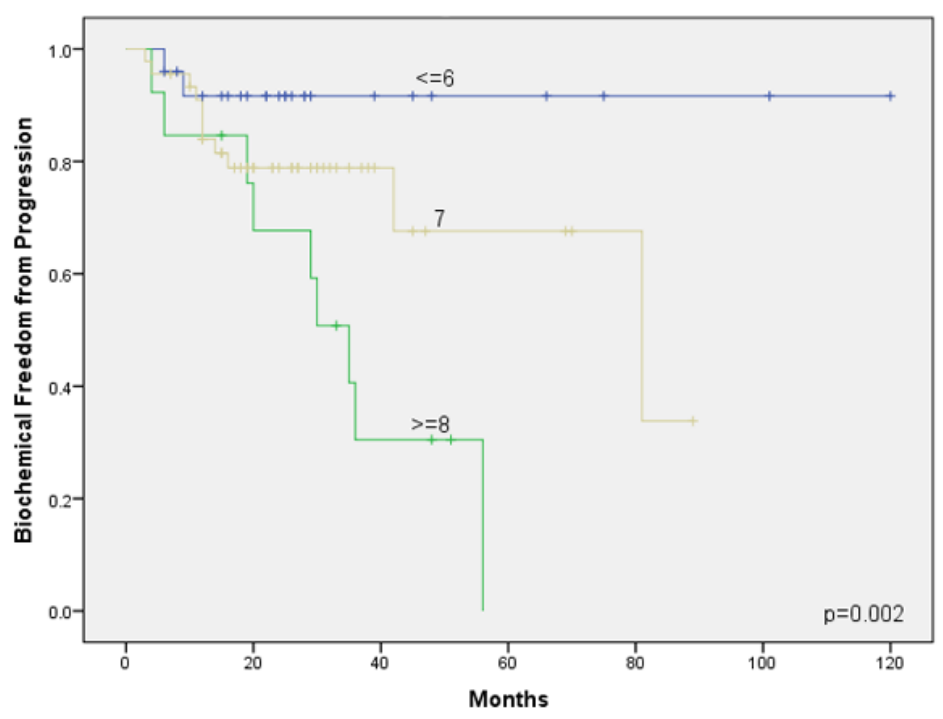


Figure 3. Product-Limit Estimate of bFFP by Pre-RT PSA

Figure 4. Product-Limit Estimate of bFFP by Post-RP PSA Nadir
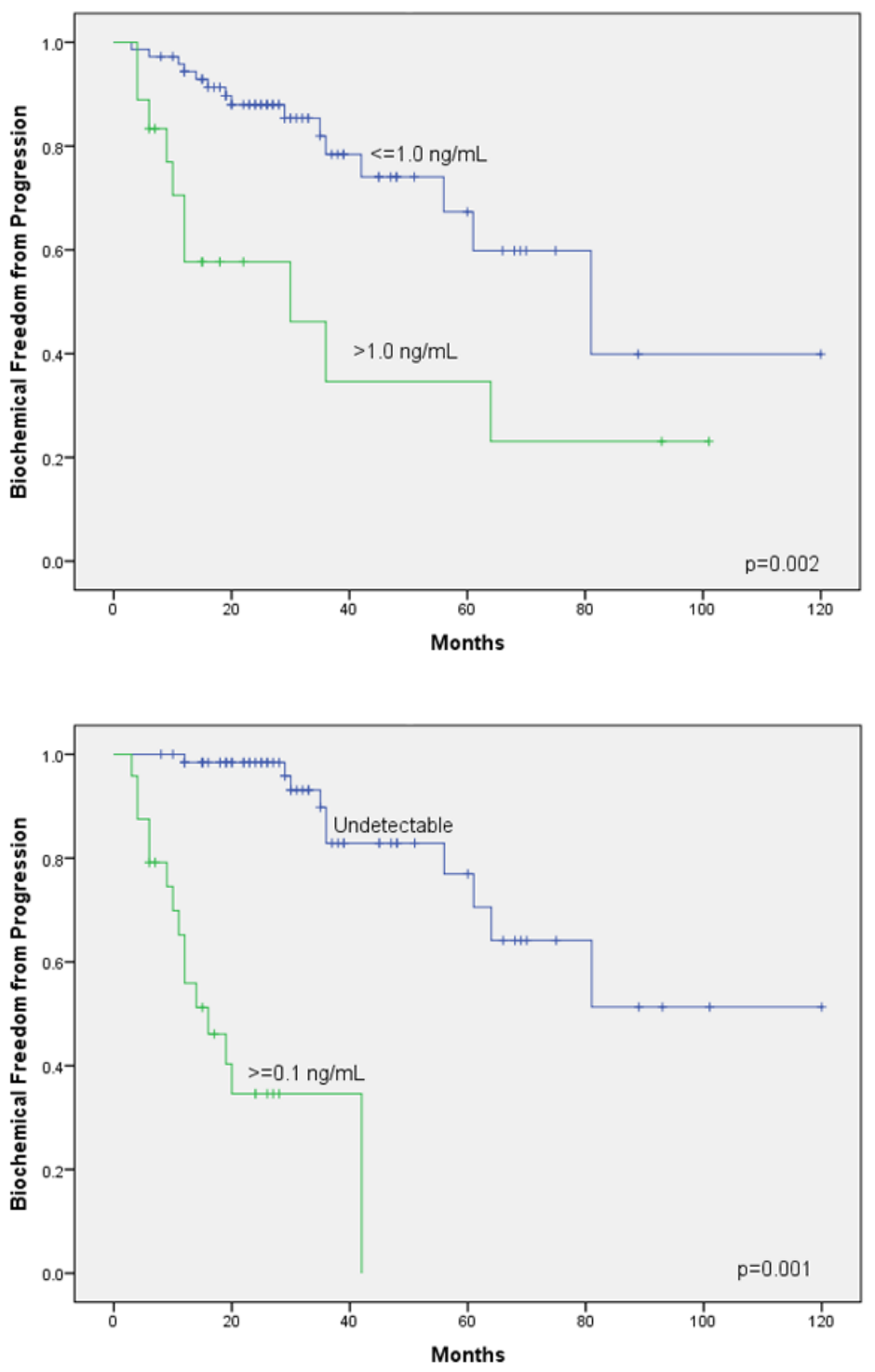

Figure 5. Product-Limit Estimate of bFFP by Intra-treatment PSA trend

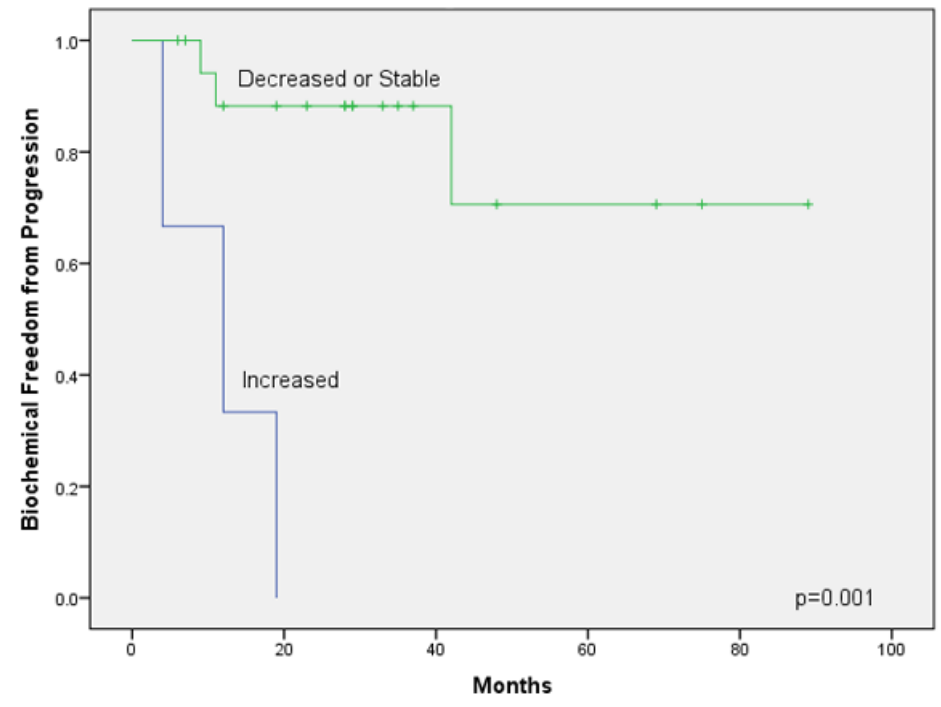




\subsection{Prognostic factors}

Univariate analyses of factors associated with biochemical progression following SRT are displayed in Table 3. The following factors were found to significantly predict biochemical progression: pathological GS $>8$, with 7 being of intermediate prognostic value between Gleason $<6$ and $>8$ (Figure 2), SVI, a length of time from prostatectomy to SRT of less than 12 months, pre-RT PSA greater than $1.0 \mathrm{ng} / \mathrm{mL}$ (Figure 3), persistently detectable PSA following RP (Figure 4), PSADT of 6 months or less, and PSAV of $1.0 \mathrm{ng} / \mathrm{mL} / \mathrm{y}$ or greater. An exploratory analysis was performed on a subgroup of 22 patients who had PSA measurements taken during SRT. PSA measurements drawn during the 5th week of treatment were compared to baseline values. Patients with a PSA trend that decreased or remained unchanged during treatment had an $88 \%$ bFFP at 3 years (Figure 5), whereas all 3 patients with a PSA that increased had failed within 20 months $(p=0.001)$. Univariate data are presented in Table 2.

Table 2. Intra-treatment subgroup characteristics $(\mathrm{n}=22)$

\begin{tabular}{|c|c|c|}
\hline & Median & Range \\
\hline Median Age, y & 60 & $48-78$ \\
\hline Median iPSA, ng/mL & 7.7 & $2.7-19.2$ \\
\hline Median Time from RP to RT, $\mathrm{m}$ & 22.5 & $3-119$ \\
\hline Median Pre-RT PSA, ng/mL & 0.55 & $0.2-2.5$ \\
\hline Median PSADT, $\mathrm{m}$ & 6.13 & $1.67-88.98$ \\
\hline \multirow[t]{2}{*}{ Median PSAV, ng/mL/y } & 0.4 & $0.04-2.7$ \\
\hline & $\mathrm{N}$ & $\%$ \\
\hline \multicolumn{3}{|l|}{ Tumor stage } \\
\hline 2 & 11 & 57.9 \\
\hline $3 a$ & 4 & 21 \\
\hline $3 \mathrm{~b}$ & 4 & 21 \\
\hline \multicolumn{3}{|l|}{ Extracapsular extension } \\
\hline Positive & 14 & 73.7 \\
\hline Negative & 5 & 26.3 \\
\hline \multicolumn{3}{|l|}{ Seminal vesicle invasion } \\
\hline Positive & 15 & 78.9 \\
\hline Negative & 4 & 21.1 \\
\hline \multicolumn{3}{|l|}{ Gleason score } \\
\hline$\leq 6$ & 8 & 36.4 \\
\hline 7 & 12 & 54.4 \\
\hline$\geq 8$ & 2 & 9.1 \\
\hline \multicolumn{3}{|l|}{ Surgical margin status } \\
\hline Positive & 12 & 63.2 \\
\hline Negative & 7 & 36.8 \\
\hline
\end{tabular}

Abbreviations: PSA, prostate-specific antigen; iPSA, pre-prostatectomy PSA; pre-RT PSA, PSADT, PSA doubling time; PSAV, PSA velocity 
Table 3. Univariate analysis of variables associated with biochemical progression free survival

\begin{tabular}{|c|c|c|}
\hline Variable & 3-Year bPFS, \% & $p$ Value \\
\hline Overall & 78 & \\
\hline \multicolumn{3}{|l|}{ Prostate Dose, Gy } \\
\hline$\geq 68.4$ & 70 & \multirow{2}{*}{0.94} \\
\hline$<68.4$ & 72 & \\
\hline \multicolumn{3}{|c|}{ Androgen deprivation therapy } \\
\hline Yes & 69 & \multirow{2}{*}{0.73} \\
\hline No & 76 & \\
\hline \multicolumn{3}{|l|}{ iPSA } \\
\hline$<10 \mathrm{ng} / \mathrm{mL}$ & 64 & \multirow{2}{*}{0.89} \\
\hline$\geq 10 \mathrm{ng} / \mathrm{mL}$ & 71 & \\
\hline \multicolumn{3}{|l|}{ Time from RP to RT } \\
\hline$\geq 12$ months & 85 & \multirow{2}{*}{0.099} \\
\hline$<12$ months & 54 & \\
\hline \multicolumn{3}{|l|}{ Pre-RT PSA } \\
\hline$>1.0 \mathrm{ng} / \mathrm{mL}$ & 34 & \multirow{2}{*}{0.004} \\
\hline$\leq 1.0 \mathrm{ng} / \mathrm{mL}$ & 82 & \\
\hline \multicolumn{3}{|l|}{ PSADT } \\
\hline$\leq 6$ months & 46 & \multirow{2}{*}{0.045} \\
\hline$>6$ months & 81 & \\
\hline \multicolumn{3}{|l|}{ PSAV } \\
\hline$>1.0 \mathrm{ng} / \mathrm{mL} / \mathrm{y}$ & 31 & \multirow{2}{*}{0.019} \\
\hline$\leq 1.0 \mathrm{ng} / \mathrm{mL} / \mathrm{y}$ & 76 & \\
\hline \multicolumn{3}{|l|}{ Tumor stage } \\
\hline $\mathrm{T} 2$ & 77 & \multirow{2}{*}{0.17} \\
\hline $\mathrm{T} 3 / 4$ & 68 & \\
\hline \multicolumn{3}{|l|}{ Extracapsular extension } \\
\hline Positive & 71 & \multirow{2}{*}{0.31} \\
\hline Negative & 75 & \\
\hline \multicolumn{3}{|l|}{ Seminal vesicle invasion } \\
\hline Positive & 46 & \multirow{2}{*}{0.059} \\
\hline Negative & 83 & \\
\hline \multicolumn{3}{|l|}{ Gleason score } \\
\hline$\leq 6$ & 92 & \multirow{3}{*}{0.01} \\
\hline 7 & 79 & \\
\hline$\geq 8$ & 38 & \\
\hline \multicolumn{3}{|l|}{ Surgical margin status } \\
\hline Positive & 66 & \multirow{2}{*}{0.60} \\
\hline Negative & 63 & \\
\hline \multicolumn{3}{|l|}{ Intra-treatment PSA ${ }^{*}$} \\
\hline Increase & 88 & \multirow{2}{*}{0.0003} \\
\hline No change/decrease & 0 & \\
\hline
\end{tabular}

Abbreviations: PSA, prostate-specific antigen; iPSA, pre-prostatectomy PSA; PSADT, PSA doubling time; PSAV, PSA velocity

*Subset of 22 patients with PSA measured during 5th week of RT 


\subsection{Multivariate analysis}

The Cox regression model included pre-RT PSA as a continuous variable, GS, tumor stage, post-prostatectomy PSA nadir, and use of neoadjuvant or concurrent ADT. Factors found to be significant predictors on univariate analysis were considered for inclusion during the regression modeling process. Though not found to be a significant predictor of bFFP on univariate analysis, use of short-course ADT was included as a potentially confounding factor due to its ability to suppress PSA values during treatment. Other variables found to be significant by univariate analysis were considered including PSADT and PSAV but were ultimately eliminated in the regression modeling process. Pre-RT PSA was shown to be a significant predictor of progression with a HR of 3.659 (CI 1.981-8.755) for each increase in PSA of $1.0 \mathrm{ng} / \mathrm{mL}$. A GS of 8 or higher was a significant predictor of progression in reference to a score of 6 or lower. The multivariate data are presented in Table 4.

Table 4. Multivariate cox regression analysis of variables associated with biochemical progression free survival

\begin{tabular}{lll}
\hline Variable & HR $(\mathbf{9 5} \% \mathbf{C I})$ & $\boldsymbol{p}$ Value \\
\hline Pre-RT PSA (continuous) & $4.164(1.981-8.755)$ & 0.00002 \\
Gleason score & & \\
$\quad \leq 6$ & Reference & 0.1111 \\
$\quad 7$ & $5.485(0.676-44.525)$ & 0.0077 \\
$\quad \geq 8$ & $21.601(2.255-206.96)$ & \\
$\quad$ & & 0.5845 \\
$\quad$ Tumor stage & $1.34(0.47-3.821)$ & 0.2971 \\
Androgen Deprivation Therapy & & \\
$\quad$ Yes & $0.465(0.11-1.961)$ & \\
\hline
\end{tabular}

Abbreviations: PSA, prostate-specific antigen

\section{Discussion}

Clinical trials have shown a positive impact on biochemical progression-free survival from adjuvant radiation in the treatment of selected patients, and subjects with positive surgical margins derived the most benefit ${ }^{[9]}$. Analyzing patterns of failure following prostatectomy, Swanson et al. found that a rising PSA is most often associated with residual local disease and that adjuvant radiation reduces the risk of biochemical failure and subsequent metastasis ${ }^{[10]}$. Data from SWOG 8794 have shown that adjuvant RT can improve metastasis-free and overall survival in patients with locally advanced disease $^{[11]}$.

While no published data from large clinical trials has established the optimal timing of post-prostatectomy RT, the RADICALS, RAVES, and GETUG-17 trials are investigating this topic ${ }^{[12-14]}$. Our data demonstrated that a length of time from prostatectomy to SRT shorter than 12 months was a predictor of poor outcome, which likely reflected the presence of aggressive disease requiring earlier salvage. Existing retrospective data have shown that SRT offers the potential for cure in patients with biochemical progression following $\mathrm{RP}^{[1]}$. The 3-year bFFP of our cohort of SRT patients was $70 \%$, which is comparable to findings in similar studies ${ }^{[6,15]}$. Variation is likely due in part to the fact that different thresholds have been used for biochemical failure. Univariate analysis of our data revealed that GS, SVI, PSADT of 6 months or less, PSAV greater than $1.0 \mathrm{ng} / \mathrm{mL} / \mathrm{y}$, and pre-RT PSA greater than $1.0 \mathrm{ng} / \mathrm{mL}$ were significant predictors of biochemical progression. 
Stephenson et al. examined 501 patients who received SRT and found that significant predictors of progression were GS of 8 to 10 , a pre-RT PSA level of $1.0 \mathrm{ng} / \mathrm{mL}$ or greater, negative surgical margins, PSADT of 10 months or less, and SVI ${ }^{[1]}$. The presence of positive margins was considered a strong predictor of response to SRT, as it suggests that biochemical progression is related to residual local disease. Our data demonstrated a trend toward decreased survival among patients with negative surgical margins $(p=0.301)$, though the sample size was inadequate to detect a difference. We also did not find an association of ECE with treatment failure, though extracapsular disease may serve as a surrogate marker of residual disease in the post-operative setting. We attempted to build upon previous work by including additional analyses of PSA kinetics, including PSADT, PSAV, and intra-treatment PSA trend. We examined pre-RT PSA as a continuous variable in our multivariate model.

Factors such as high GS, SVI, and rapid PSA kinetics indicate the presence of aggressive disease that is prone to metastasis ${ }^{[16-17]}$. The findings from our study support this assertion. We examined two measures of post-prostatectomy PSA kinetics, PSADT and PSAV. Previous work has shown that PSAV independently predicts for biochemical failure after SRT ${ }^{[6]}$. King et al. assert that PSAV is a better predictor of progression than PSADT in the post-RP setting because the majority of the patients have local recurrence, which they hypothesize follows zero-order kinetics. Our data found an association of both measures with biochemical progression.

Patients with a pre-RT PSA greater than $1.0 \mathrm{ng} / \mathrm{mL}$ had a 3-year bFFP of $34 \%$ compared with $82 \%$ in patients with a value of $1.0 \mathrm{ng} / \mathrm{mL}$ or less. On multivariate analysis, an increase in pre-RT PSA of $1.0 \mathrm{ng} / \mathrm{mL}$ was associated with a four-fold increase in biochemical failure. PSA progression is associated with an increased risk of distant metastasis ${ }^{[16]}$. Patients who receive early SRT are more likely to achieve long-term biochemical control and, therefore, will have a decreased risk of distant disease spread. The association of pre-RT PSA with biochemical failure demonstrates the importance of early salvage treatment for patients with rising PSA.

Five-year biochemical control rates after SRT have been reported between $35 \%$ and $67 \%{ }^{[18-22]}$. While the presence of high-risk features suggests the need for early SRT, a significant proportion of patients with rising PSA post-prostatectomy will not benefit from SRT. This implies a need for better methods to assess which patients are likely to benefit from treatment. Though researchers have identified pathologic characteristics that are associated with a good response to SRT, there is no available method to accurately distinguish between post-operative patients with biochemical recurrence from the presence of local disease versus distant spread.

We examined the association between post-prostatectomy PSA nadir and biochemical control and found that patients with persistently detectable PSA levels had a 55\% 3-year bFFP compared with 79\% in those who reached an undetectable nadir. Patients who reached an undetectable PSA nadir likely had microscopic local residual disease, which was demonstrated by fact that SRT to the prostate fossa caused serum PSA to decline to an undetectable level. The presence of local residual disease may account for the fact that patients who reached an undetectable nadir fared better in terms of bFFP, while patients with persistently detectable PSA may have had occult metastasis. Many patients whose PSA did not fall to undetectable levels did achieve a durable response to SRT, which implies that the persistent serum PSA seen in these patients was produced by residual local disease. The greater propensity for biochemical failure, however, suggests that an inability to reach an undetectable PSA is associated with an increased probability of harboring occult distant disease.

We performed an exploratory analysis on a subset of patients who had PSA levels drawn at the 5th week of SRT and compared these values to baseline levels taken prior to RT with the expectation that intra-treatment PSA response may be associated with biochemical control. Previous work has shown that PSA levels increase during radiation in patients with intact prostatic tissue, which is likely due to the death of healthy acinar cells and the subsequent release of PSA into the bloodstream ${ }^{[24]}$. Post-prostatectomy patients, however, should not have sufficient normal glandular tissue to demonstrate this response. Given its short half-life ${ }^{[25]}$, serum PSA levels may decrease during radiation treatment in patients with 
microscopic residual disease, whereas patients with metastatic spread should not demonstrate a PSA response to localized treatment.

Do et al. prospectively followed 41 patients treated with SRT who had PSA levels drawn during treatment ${ }^{[26]}$. They found that while PSA elevations at 30 Gy did not significantly predict for outcome, PSA elevations at 45 Gy were associated with both biochemical and clinical failure. The authors postulated that patients with a rising PSA during treatment are likely to have occult metastasis, but they cautioned that local disease may still be present in these patients. A similar analysis performed by Youssef et al. found that patients whose PSA increased by more than $0.2 \mathrm{ng} / \mathrm{mL}$ during treatment had a 5 -year bFFP of $10 \%$ compared to $43 \%$ in patients whose PSA decreased or remained stable ${ }^{[27]}$. They concluded that in the absence of benign prostatic tissue, PSA trend during RT is of significant prognostic value. The authors recommended discontinuation of radiation at 45-50 Gy in patients with rising PSA levels.

Our own data showed that rising PSA during treatment was predictive of biochemical failure. The subgroup of 22 patients who had PSA levels measured during treatment demonstrated a 3-year bFFP of 75\%. The subgroup patients' pathological characteristics were representative of the rest of the cohort. The patients whose PSA decreased during treatment or remained unchanged had a 3 -year bFFP of $88 \%$. All 3 patients who demonstrated an increase in PSA progressed biochemically within 20 months.

The 3 patients with rising PSA had tumors with aggressive features that are known to predispose to distant metastasis. They may have had occult systemic disease at the time of treatment, which was demonstrated by their lack of response to SRT. At the time of this analysis, one of these 3 patients had developed clinically apparent metastatic disease. These findings suggest that patients with aggressive disease who demonstrate a rising PSA during SRT are less likely to respond to local treatment alone, and clinical trials using including systemic therapy may be considered. Further prospective research is needed to confirm these findings.

Acknowledged limitations of this study include its retrospective nature with inherent problems of selection bias. Though we attempted to control for the lack of uniform treatment in the multivariate analysis, heterogeneity may still serve as a confounding factor. Additional weaknesses include the size sample size, and the intra-treatment PSA data should be interpreted with caution given the small number of patients analyzed. Although the characteristics of the subgroup were representative of the other subjects, it cannot be determined whether or not the rate of biochemical failure seen in patients with an increasing PSA trend merely reflected the presence of more aggressive disease. While our series reflects a small number of patients, the results are provocative. Additional prospective work examining a larger sample of patients is needed to evaluate this question.

\section{Conclusion}

Our data demonstrate a 70\% 3-year bFFP in patients treated with SRT. Factors significantly associated with progression included a high GS, SVI, persistently detectable PSA after RP, short time from RP to RT, pre-RT PSA greater than 1.0 $\mathrm{ng} / \mathrm{mL}$, PSADT of 6 months or less, PSAV greater than $1.0 \mathrm{ng} / \mathrm{mL} / \mathrm{y}$, and rising PSA during SRT. The demonstrated significance of pre-RT PSA as a prognostic factor in Univariate and multivariate analyses suggests that early consideration of SRT should be given for patients with high-risk features and/or rising PSA. An exploratory analysis demonstrated that post-operative patients with a rising PSA level during treatment are prone to earlier progression than those with stable or decreasing trends. While the sample size was small, the results suggest the need for future prospective work to confirm these findings. Clinical trials including systemic therapy should be considered for patients with persistently detectable PSA after RP or a rising PSA trend during SRT.

\section{Declaration of interest}

The authors declare that they have no competing interests. 


\section{References}

[1] Stephenson AJ, Shariat SF, Zelefsky MJ, et al. Salvage radiotherapy for recurrent prostate cancer after radical prostatectomy. JAMA. 2004; 291(11):1325-32. PMid:15026399 http://dx.doi.org/10.1001/jama.291.11.1325

[2] Trock BJ, Han M, Freedland SJ, et al. Prostate cancer-specific survival following salvage radiotherapy vs observation in men with biochemical recurrence after radical prostatectomy. JAMA. 2008; 299(23):2760-9. PMid:18560003 http://dx.doi.org/10.1001/jama.299.23.2760

[3] Cox JD, Gallagher MJ, Hammond EH, et al. for the American Society for Therapeutic Radiology and Oncology Consensus Panel: Consensus statements on radiation therapy of prostate cancer: guidelines for prostate-rebiopsy after radiation and for radiation therapy with rising prostate-specific antigen levels after radical prostatectomy. J Clin Oncol. 1999; 17(4):1155-63. PMid:10561174

[4] Stephenson AJ, Scardino PT, Kattan MW, et al. Predicting the outcome of salvage radiation therapy for recurrent prostate cancer after radical prostatectomy. J Clin Oncol. 2007; 25(15):2035-41. PMid:17513807 http://dx.doi.org/10.1200/JCO.2006.08.9607

[5] Soto DE, Andridge RR, Pan CC, et al. Determining if pretreatment psa doubling time predicts psa trajectories after radiation therapy for localized prostate cancer. Radiotherapy and Oncology. 2009; 90(3):389-94. PMid:18977051 http://dx.doi.org/10.1016/j.radonc.2008.09.014

[6] King CR, Presti JC, Brooks JD, et al. Postoperative prostate-specific antigen velocity independently predicts for failure of salvage radiotherapy after prostatectomy. Int J Rad Oncol Biol Phys. 2008; 70(5):1472-7. PMid:17935902 http://dx.doi.org/10.1016/j.ijrobp.2007.08.014

[7] Prostate Cancer Nomograms: PSA Doubling Time. Prediction Tools. Memorial Sloan-Kettering Cancer Center. http://nomograms.mskcc.org/Prostate/PsaDoublingTime.aspx

[8] Amling CL, Bergstralh EJ, Blute ML, et al. Defining prostate-specific antigen progression after radical prostatectomy: what is the most appropriate cut point? J Urol. 2001;165(4): 1146-51. http://dx.doi.org/10.1016/S0022-5347(05)66452-X

[9] Van der Kwast TH, Bolla M, Van Poppel H, et al. Identification of patients with prostate cancer who benefit from immediate postoperative radiotherapy: EORTC 22911. J Clin Oncol. 2007; 25(27):4178-86. PMid:17878474

[10] Swanson GP, Hussey MA, Tangen CM, et al. Predominant treatment failure in postprostatectomy patients is local: analysis of patterns of treatment failure in SWOG 8794. J Clin Oncol 2007; 25(16):2225-9. PMid:17538167 http://dx.doi.org/10.1200/JCO.2006.09.6495

[11] Thompson IM, Tangen CM, Paradelo J, et al. Adjuvant radiotherapy for pathological T3N0M0 prostate cancer significantly reduces risk of metastases and improves survival: long-term followup of a randomized clinical trial. JUrol 2009;181(3):956-62. PMid:19167731 http://dx.doi.org/10.1016/j.juro.2008.11.032

[12] RADICALS. Radiotherapy and androgen deprivation in combination after local surgery. A randomized controlled trial in prostate cancer.Medical Research Council Clinical Trials Unit [Internet]. 2007 Apr 17 [cited 2013 Jan 10]. Available from: http://www.radicals-trial.org

[13] Radiotherapy adjuvant versus early salvage. Trans-Tasman Radiation Oncology Group [Internet]. 2008 Aug 7 [cited 2012 Jan 10]. Available from: http://www.trog-raves.org/Documents/RAVES\%20section\%208\%20protocol\%20RT\%20amended\%202011.pdf

[14] Triptorelin and radiation therapy in treating patients who have undergone surgery for intermediate-risk Stage III or Stage IV prostate Cancer. National Cancer Institute [Internet]. 2008 Apr 24[cited 2013 Jan 10]. Available from: http://clinicaltrials.gov/show/NCT00667069.

[15] Meerleer GD, Fonteyne V, Meersschout S, et al. Salvage intensity-modulated radiotherapy for rising PSA after radical prostatectomy. Radiotherapy and Oncology. 2008; 89(2): 205-13. PMid:18771809 http://dx.doi.org/10.1016/j.radonc.2008.07.027

[16] Pound CR, Partin AW, Eisenberger MA, et al. Natural history of progression after PSA elevation following radical prostatectomy. JAMA. 1999; 281(17): 1591-97. PMid:10235151 http://dx.doi.org/10.1001/jama.281.17.1591

[17] D'Amico AV, Cote K, Loffredo M, et al. Determinants of prostate cancer-specific survival after radiation therapy for patients with clinically localized prostate cancer. J Clin Oncol. 2002; 20(23): 4567-73. PMid:12454114 http://dx.doi.org/10.1200/JCO.2002.03.061

[18] Chawla AK, Thakral HK, Zietman AL, Shipley WU. Salvage radiotherapy after radical prostatectomy for prostate adenocarcinoma: analysis of efficacy and prognostic factors. J Urol. 2002; 59(5): 726-31. http://dx.doi.org/10.1016/S0090-4295(02)01540-6

[19] Bernard JR, Buskirk SJ, Heckman MG, et al. Salvage radiotherapy for rising prostate-specific antigen levels after radical prostatectomy for prostate cancer: dose-response analysis. Int J Rad Oncol Biol Phys. 2010; 76 (3): 735-40. PMid:19464818 http://dx.doi.org/10.1016/j.ijrobp.2009.02.049

[20] Goenka A, Magsanoc JM, Pei X, et al. Long term outcomes after high-dose postprostatectomy salvage radiation treatment. Int J Rad Oncol Biol Phys. 2011 E-publication. 
[21] Buskirk SJ, Pisansky TM, Schild SE, et al. Salvage radiotherapy for isolated prostate specific antigen increase after radical prostatectomy: evaluation of prognostic factors and creation of a prognostic scoring system. J Urol. 2006;176(3): 985-90. PMid:16890677 http://dx.doi.org/10.1016/j.juro.2006.04.083

[22] Nudell DM, Grossfeld GD, Weinberg VK, et al. Radiotherapy after radical prostatectomy: treatment outcomes and failure patterns. Urology. 1999; 54(6): 1049-57. http://dx.doi.org/10.1016/S0090-4295(99)00299-X

[23] Nagda SN, Mohideen N, Lo SS, et al. Long-term follow-up of111-In-capromab pendetide (Prostascint) scan as pretreatment assessment in patients who undergo salvage radiotherapy for rising prostate-specific antigen after radical prostatectomy for prostate cancer. Int J Rad Oncol Biol Phys. 2007; 67(3):834-840. PMid:17293236 http://dx.doi.org/10.1016/j.ijrobp.2006.09.026

[24] Vijayakumar S, Quadri SF, Sen S, et al. Measurement of weekly prostate specific antigen levels in patients receiving pelvic radiotherapy for nonprostatic malignancies. Int J Rad Oncol Biol Phys. 1995; 32(1): 189-95. http://dx.doi.org/10.1016/0360-3016(94)00460-3

[25] Oesterling JE. Prostate specific antigen: a critical assessment of the most useful tumor marker for adenocarcinoma of the prostate. J Urol. 1991; 145: 907-923. PMid:1707989

[26] Do T, Dave G, Parker R, et al. Serum psa evaluations during salvage radiotherapy for post-prostatectomy biochemical failures as prognosticators for treatment outcomes. Int J Rad Oncol Biol Phys. 2001; 50 (5): 1220-5. http://dx.doi.org/10.1016/S0360-3016(01)01558-9

[27] Youssef E, Forman JD, Tekyi-Mensah S, et al. Therapeutic postprostatectomy irradiation. Clin Prostate Cancer. 2002; 1(1):31-6. PMid:15046710 http://dx.doi.org/10.3816/CGC.2002.n.004 